\title{
ТРУДНОСТИ РАННЕЙ ДИАГНОСТИКИ И ОПЕРАТИВНОЙ КОРРЕКЦИИ ТЯЖЕЛОГО ВРОЖДЕННОГО ПОРОКА СЕРДЦА - ОБЩЕГО ОТКРЫТОГО АТРИОВЕНТИКУЛЯРНОГО КАНАЛА У РЕБЕНКА ПЕРВОГО ГОДА ЖИЗНИ (КЛИНИЧЕСКИЙ СЛУЧАЙ)
}

Врожденные пороки сердца (ВПС) - это аномалии морфологического развития сердца, его клапанного аппарата и магистральных сосудов, возникшие на 2-8-й неделе внутриутробного развития в результате нарушения процессов эмбриогенеза. Эти дефекты могут встречаться изолированно или в сочетании друг с другом. [5]. Общая распространенность ВПС составляет 8 на 1000 родов (5,6 - 15,32 в зависимости от страны) и 7,2 на 1000 живорожденных. Общая частота нехромосомных ВПС составляет 7 на 1000 родов, из которых 3,6\% составляют перинатальные потери, 20\% диагностируются пренатально, 5,6\% беременностей прерывается в связи с выявленной аномалией плода. Сложные нехромосомные пороки сердца (то есть, исключая дефект межжелудочковой перегородки, дефект межпредсердной перегородки, стеноз легочной артерии) составляют 2 на 1000 родов. Исходом в 8,1\% случаев становится перинатальная смерть, $40 \%$ диагностируются внутриутробно, 14\% становятся причиной прерывания беременности (от 0\% до 32\% в зависимости от страны). Около 12\% ВПС ассоциируются с хромосомными аномалиями (7\% с синдромом Дауна, 2\% с синдромом Эдвардаса и $1 \%$ с синдромом Патау), составляя 0,97 случаев на 1000 родов. ВПС, ассоциированный с синдромом Дауна, встречается в 3-19\% всех педиатрических ВПС в зависимости от страны. Таким образом, нехромосомные ВПС составляют 6,5 случаев на 1000 живых новорожденных. [5].

Основными проявлениями ВПС являются одышка, цианоз или бледность кожи, шум в области сердца, отставание ребенка в физическом развитии, частые респираторные заболевания.

Наиболее распространенным и точным методом диагностики ВПС является эхокардиография (ЭхоКГ), а также зондирование сердца и магистральных сосудов, исследование с использованием рентгенконтрастных веществ, в том числе магнитно-резонансная томография в ангиорежиме.

Около 40 \% детей с ВПС нуждаются в оперативном вмешательстве на первом году жизни. Хирургическая коррекция ВПС проводится как на «работающем» сердце, так и с использованием аппарата искусственного кровообращения. Коррекция некоторых пороков возможна с использованием эндоваскулярных методик. 95 \% ВПС успешно оперируются. В то же время существуют редкие формы ВПС комбинированные, осложненные, летальность при которых достаточно высокая, особенно у детей первых месяцев жизни.

К таковым относится редкий ВПС: общий открытый атриовентрикулярный канал (OO$\mathrm{ABK})$ или атриовентрикулярный септальный дефект (АВСД), или дефект эндокардиальных подушечек, который отмечается гетерогенностью и включает большую группу аномалий, объединенных одним анатомическим признаком: дефектом мышечной и мембранозной атриовентикулярной перегородки (AV-перегородки) от межпредсердного сообщения до функционально единственного желудочка. Этот порок составляет 4 \% от всех ВПС. У 75 \% больных с ООАВК констатируют синдром Дауна. [5]. Главным анатомическим признаком ООАВК является выраженный в большей или меньшей степени дефект мембранозной и мышечной AV-перегородок. Выделяют полную и неполную форму ООАВК. Полная форма включает в себя высокорасположенный большой мембранозный дефект межжелудочковой перегородки, низкорасположенный большой первичный дефект межпредсердной перегородки и общий атриовентрикулярный клапан со сложным единым аномальным

(c) С.М. Максимова, С.И. Вакуленко, Н.В. Максимова,
Т. Халабузарь, 2020

(c) Университетская Клиника, 2020 
створчатым аппаратом (расщепление одной из створок митрального или трикуспидального клапана). Данный порок сердца часто сочетается с трисомией по 21 хромосоме. При этом пороке гемодинамические нарушения характеризуются преимущественно лево-правым сбросом крови как на уровне желудочков, так и на уровне предсердий, а также выраженной гиперволемией малого круга кровообращения. Из-за того, что межпредсердный и межжелудочковый дефекты большие, давление во всех камерах сердца быстро выравнивается. Объем сброса определяется: 1) степенью растяжимости отдельных камер сердца (правое предсердие обладает большей растяжимостью); 2) мощностью желудочков (левый желудочек более мощный); 3) градиентом давлений между аортой и легочной артерией. В результате выраженной объемной перегрузки правых отделов сердца формируется кардиомегалия и расширение легочной артерии, быстро развивается легочная гипертензия. В клинической картине рано (уже на первой неделе жизни) развивается сердечная недостаточность: одышка, застойные хрипы в легких, отечный синдром. К 3-4 месяцам формируется бивентрикулярный (сердечный) «горб», расширение границ относительной сердечной тупости. Выслушивается различной интенсивности систолический шум (от выраженного до практически отсутствующего при т.н. «немой форме»), без четкой локализации, хорошо иррадиирующий во все отделы грудной клетки, в том числе и на спину. Быстро формируется акцент II тона над легочной артерией. Выражена гепатоспленомегалия. Дети очень плохо прибавляют в весе, развивается пневмония.

На рентгенограмме определяется кардиомегалия со значительным расширением легочной артерии, выражена гиперволемия малого круга кровообращения. На электрокардиограмме (ЭКГ): отклонение электрической оси сердца влево при одновременной гипертрофии правых отделов. Часто встречаются атриовентрикулярные блокады. Допплер-ЭхоКГ (ДЭхоКГ) позволяет определить размеры и локализацию ДМЖП и ДМПП, наличие щели между митральным и трикуспидальным клапанами. Диагностически значимым является определение повышенного давления в правом желудочке и легочной артерии. При естественном течении порока сердца летальный исход наступает очень быстро. Наличие такого ВПС является абсолютным показанием к операции. Без оперативного вмешательства неуклонно нарастает тотальная сердечная недостаточность, рефрактерная к медикаментозному лечению. Радикальная операция проводится в условиях искусственного кровообра- щения (ИК), гипотермии тела до $20-22^{\circ} \mathrm{C}$ и включает в себя пластику ДМЖП и ДМПП, разделение атриовентрикулярного кольца на правое и левое, устранение недостаточности предсердножелудочковых клапанов. Хирургическое лечение показано всем больным из-за выраженных нарушений кровообращения. Операцию выполняют между 3 и 8 месяцами жизни в зависимости от тяжести состояния пациента. Особенно важна ранняя операция в первые 3 месяца жизни у детей с сопутствующим синдромом Дауна. Традиционную двухэтапную коррекцию полного ООАВК (в раннем младенчестве) стали проводить в 1970-1980-х годах даже у детей с массой тела менее 2,5 кг. Это стало возможным благодаря эволюции хирургического лечения от двухэтапного до первичной полной коррекции с использованием ЭхоКГ в пред-, интра- и послеоперационном периоде. Особенно сложной проблемой до- и послеоперационного периода была и остается сужение выводного тракта левого желудочка, которое наблюдается при всех формах ООABК и не исключает необходимости повторных хирургических вмешательств. При этом специфическими факторами риска у больных с ООABK являются такие, как: гипоплазия желудочков, двойное отверстие левого AV-канала, парашютообразная деформация AV-клапана, сочетание с другими ВПС (тетрада Фалло, аномалия Эбштейна и др.).

Группа австралийских хирургов в 1995-1999 годах у оперированных 47 пациентов впервые использовала дакроновую полоску в качестве одной заплаты для уменьшения размера кольца на уровне межжелудочковой перегородки. Несколько позднее в период между 1997 и 2002 гг. в детском госпитале Бостона была использована эта техника у 34 больных с полным ООАВК. Летальных исходов не было. Ни у одного из оперированных не развилось сужение выводного тракта левого желудочка и по данным ЭхоКГ в раннем и отдаленном послеоперационном периодах не было выраженной недостаточности клапана. Таким образом, авторы пришли к выводу, что модифицированная техника с использованием одной заплаты сохраняет целостность створок AV-клапана без стенозирования выводного тракта левого желудочка и ухудшения качества коррекции клапана даже при большом ДМЖП и несбалансированном ООАВК с единственной папиллярной мышцей. Преимущество этой техники также в том, что она может применяться даже у новорожденных. Кроме того, австралийская техника позволяет сократить время перфузии и окклюзии аорты. Отдаленные результаты аналогичны тем, которые были получены при стандартной коррекции. 
Клинический случай.РебенокД., 4 месяца, родился от I беременности, протекавшей на фоне анемии. Интранатально выполнено ЭхоКГ плода - патологии со стороны сердечно-сосудистой системы не выявлено. Ребенок от I срочных физиологических родов (38 недель гестации). Масса при рождении - 3000 г, длина - 54 см. Оценка по шкале Апгар - 7/8 баллов. В роддоме фенотипически был заподозрен синдром Дауна, отмечался синдром угнетения. От генетического исследования и перевода в отделение патологии новорожденных родители отказались. Выписан из роддома на 4-е сутки. На 6-е сутки жизни ребенок в связи с дефицитом массы тела (13,3 \%), общей вялостью и отказом от груди доставлен бригадой скорой помощи в Республиканскую детскую клиническую больницу, отделение патологии новорожденных. Была предложена госпитализация, от которой родители отказались.

В возрасте 2,5 месяца на плановом осмотре педиатр впервые выслушал шум над областью сердца, после чего ребенок был направлен на ЭхоКГ, по результатам которого выявлены изменения: полная форма ООАВК: ДМПП - 10 мм, ДМЖП - 10 мм, давление в легочной артерии 45,0 мм.рт.ст., недостаточность МК - II-III степени, недостаточность ТК I степени. В связи с выявленными изменениями мальчик был консультирован кардиохирургом ИНВХ им. В.К. Гусака, выставлен диагноз: ВПС: общий открытый атриовентрикулярный канал (дефект межжелудочковой перегородки, большой первичный дефект межпредсердной перегородки по типу общего предсердия). Недостаточность митрального клапана II-III степени. Сбалансированная форма открытого артериального протока. Недостаточность трикуспидального клапана I степени. Легочная гипертензия II степени (давление в легочной артерии (ЛА) - 45,0 мм.рт.ст.). СНІІа. Назначена терапия: ингибиторы ангиотензинпревращающего фермента, калийсберегающие и петлевые диуретики. Повторный осмотр с результатами ЭхоКГ через 2 месяца. Родители дома лечение не проводили.

В возрасте 4-х месяцев повторно проведено ЭхоКГ - отрицательной динамики не наблюдалось. В весе прибавлял недостаточно. После повторной консультации кардиохирурга, ребенок госпитализирован в отделение детской кардиологии и кардиохирургии ИНВХ им. В.К. Гусака для дообследования, решения вопроса об оперативной коррекции врожденного порока сердца. В отделении проведена коррекция медикаментозной терапии, добавлены сердечные гликозиды. В связи с отсутствием возможности кардиохирургической коррекции ВПС по месту жи- тельства ребенок был направлен в кардиохирургический центр Российской Федерации.

При поступлении в кардиохирургическое отделение состояние ребенка средней степени тяжести, обусловлено явлениями сердечнососудистой недостаточности. Выражен фенотип синдрома Дауна. Кожные покровы и видимые слизистые бледно-розовые, элементы потницы. Над легкими дыхание пуэрильное, проводится во все отделы, хрипов нет. ЧД - 46 в минуту. Тоны сердца громкие, ритмичные. Систолический шум средней интенсивности над областью сердца. ЧСС - 134 удара в минуту. АД 102/58 мм.рт.ст. Пульсация на периферических сосудах удовлетворительная. Живот мягкий, безболезненный. Печень на 2,0 см выступает изпод края реберной дуги. Селезенка не пальпируется. Мочеиспускание свободное. Мочится достаточно, диурез стимулирован калийсберегающими и петлевыми диуретиками. Стул самостоятельный. Видимых отеков, пастозности нет.

В отделении проведено дополнительное обследование:

Общий анализ крови, биохимический анализ крови, коагулограмма, общий анализ мочи - без особенностей.

ЭхоКГ: левый AB-клапан четырехстворчатый, левая створка имеет дополнительное расщепление. Клапан аорты - трехстворчатый, створки тонкие, подвижные. Правый атриовентрикулярный клапан - трех-четырехстворчатый, створки тонкие, подвижные. Клапан легочной артерии: трехстворчатый, створки тонкие, подвижные. ДМЖП приточный типа АВК 10×16 мм, ДМПП первичный и вторичный $15 \times 21$ мм, вторичная перегородка диспластичная, тонкая, представлена только верхним краем. В полости ЛЖ две группы папиллярных мышц. Хорды верхней левой мостовидной створки не крепятся к гребню МЖП, она не разделена.

ЭКГ: ритм синусовый, с ЧСС 136-143 удара в минуту. Перегрузка правых отделов сердца.

Рентгенография органов грудной клетки: очаговых и инфильтративных теней не определяется. Кардиоторакальный индекс (КТИ) - 64 $\%$.

Согласно вышеперечисленных данных ребенку выставлен диагноз: Situs solitus. ВПС: общий открытый атриовентикулярный канал, тип С по Растелли. Умеренная недостаточность общего атриовентрикулярного клапана. Вторичный ДМПП. Высокая легочная гипертензия. II функциональный класс по Ross. Синдром Дауна. Задержка темпов физического и моторного развития. Рахит I степени.

В возрасте 6 месяцев ребенку проведена радикальная коррекция порока с использовани- 
ем модифицированной «австралийской» техники: пластика ДМЖП, пластика левого и правого атриовентрикулярного клапана, пластика ДМПП заплатой из перикарда в условиях искусственного кровообращения и кардиоплегии. В раннем послеоперационном периоде у ребенка отмечался ателектаз верхней доли левого легкого, перикардиотомный синдром, но на фоне проведенной интенсивной терапии к моменту выписки из отделения на 6-е сутки после операции сердечно-легочная деятельность удовлетворительная. На контрольной рентгенограмме органов грудной клетки: легкие расправлены, очаговые и инфильтративные тени не определяются. Синусы плевры свободны. Корни расширены. КТИ $=54$ \%. Исход заболевания - улучшение по ВПС.

При выписке из кардиохирургического отделения ребенку рекомендовано динамическое наблюдение педиатра, кардиолога, кардиохирур- га, плановое ЭхоКГ-исследование через 2 недели после выписки (контроль жидкости), повторный общий анализ крови, мочи, отвод от профилактических прививок на 6 месяцев, продолжить прием калийсберегающих диуретиков (верошпирон) и ингибиторов ангиотензипревращающего фермента (капотен) под контролем АД в течение 5 месяцев. Все указанные рекомендации родители выполняли не в полном объеме.

Таким образом, несмотря на определенные трудности ранней диагностики тяжелого врожденного порока сердца у данного пациента все же своевременная коррекция порока с использованием «австралийской» технологии позволила сохранить жизнь ребенку без тяжелых необратимых осложнений в послеоперационном периоде. Не менее важным является своевременное диспансерное наблюдение ведущих специалистов по месту жительства: педиатра, кардиолога, кардиохирурга, психоневролога.

\section{С.М. Максимова, С.И. Вакуленко, Н.В. Максимова, Т. Халабузарь}

ГОО ВПО «Донецкий национальный медицинский университет имени М. Горького», Донецк

\section{ТРУДНОСТИ РАННЕЙ ДИАГНОСТИКИ И ОПЕРАТИВНОЙ КОРРЕКЦИИ ТЯЖЕЛОГО ВРОЖДЕННОГО ПОРОКА СЕРДЦА - ОБЩЕГО ОТКРЫТОГО АТРИОВЕНТИКУЛЯРНОГО КАНАЛА У РЕБЕНКА ПЕРВОГО ГОДА ЖИЗНИ (КЛИНИЧЕСКИЙ СЛУЧАЙ)}

Общий открытый атриовентрикулярный канал (ООАВК) или атриовентрикулярный септальный дефект (АВСД) включает большую группу аномалий, объединенных одним анатомическим признаком: дефицитом мышечной и мембранозной атриовентикулярной перегородки (AV-перегородки) от межпредсердного сообщения до функционально единственного желудочка. Этот порок составляет $4 \%$ от всех ВПС. У 75 \% больных с ООАВК констатируют синдром Дауна. В данной статье рассмотрен клинический случай ребенка с ООАВК, сочетающегося с синдромом
Дауна. После тщательного обследования, уточнения диагноза ребенку проведена оперативная коррекция данного порока по модифицированной «австралийской» технике. Авторы обращают внимание на трудности ранней диагностики тяжелого врожденного порока сердца.

Ключевые слова: врожденный порок сердца, атриовентрикулярный канал, дефект межжелудочковой перегородки, дефект межпредсердной перегородки, расщепление атриовентрикулярных клапанов.

\section{S.M. Maksimova, S.I. Vakulenko, N.V. Maksimova, T. Khalabuzar}

SEI HPE «M. Gorky Donetsk National Medical University», Donetsk

\section{DIFFICULTIES OF EARLY DIAGNOSTICS AND OPERATIONAL CORRECTION OF HEAVY CONGENITAL HEARTH DISEASES - COMMON OPEN ATRIOVENTICULAR CANAL IN A CHILD OF THE FIRST YEAR OF LIFE (CLINICAL CASE)}

The common open atrioventricular canal (COAVC) or atrioventricular septal defect (AVSD) includes a large group of anomalies combined by one anatomical symptom: a deficit of muscle and membranous atrioventricular septum (AV-septum) from the interatrial septum fenestration to a functional single ventricle. This defect is $4 \%$ of all congenital heart diseases. In $75 \%$ of patients with COAVC Down syndrome is noted. The clinical case of a child with COAVC, combined with Down syndrome is described. After a thorough examination, clarification of the diagnosis, the child underwent an operative correction of this defect according to the modified "Australian" technique. The authors draw attention to the difficulties of early diagnosis of severe congenital heart disease.

Key words: congenital heart disease, atrioventricular canal, ventricular septal defect, interatrial septum defect, splitting of atrioventricular valves. 


\section{ЛИТЕРАТУРА}

1. Зиньковский М.Ф. Врожденные пороки сердца. Киев: Книга «Плюс»; 2009: 247-271.

2. Белоконь Н.А., Кубергер М.Б. Врожденные пороки сердца и сосудов у детей. Руководство для врачей. Том 1. Москва: Медицина; 1987: 216-300.

3. Симонова Л.3. Врожденные пороки сердца у детей. В кн.: Лекции по педиатрии. Том 4 «Кардиология». Москва; 2004: 126-166.

4. Mavroudis Constantine, Backer Carl L. Pediatric Cardiac Surgery. Wiley- Blackwell; 2013: 342-354.

5. Федеральные клинические рекомендации пооказанию медицинской помощи детям сврожденными пороками сердца. Союз педиатров России, Ассоциация детских кардиологов России. 2015. http://www.pediatr-russia.ru

\section{REFERENCES}

1. Zin'kovskii M.F. Vrozhdennye poroki serdtsa. Kiev: Kniga «Plyus»; 2009: 247-271 (in Russian).

2. Belokon' N.A., Kuberger M.B. Vrozhdennye poroki serdtsa i sosudov u detei. Rukovodstvo dlya vrachei. Tom 1. Moskva: Meditsina; 1987: 216-300 (in Russian).

3. Simonova L.Z. Vrozhdennye poroki serdtsa u detei. V kn.: Lektsii po pediatrii. Tom 4 «Kardiologiya». Moskva; 2004: 126-166 (in Russian).

4. Mavroudis Constantine, Backer Carl L. Pediatric Cardiac Surgery. Wiley- Blackwell; 2013: 342-354.

5. Federal'nye klinicheskie rekomendatsii pookazaniyu meditsinskoi pomoshchi detyam svrozhdennymi porokami serdtsa. Soyuz pediatrov Rossii, Assotsiatsiya detskikh kardiologov Rossii. 2015. http://www.pediatr-russia.ru (in Russian). 